\title{
EU VO LÁ ONTEM, PAPAI! - EXPERIÊNCIA E CULTURAS INFANTIS: REFLEXÕES SOBRE INFÂNCIA E TEMPORALIDADE RECURSIVA
}

\author{
Eduardo Oliveira Sanhces ${ }^{1}$ \\ Divino José DA SILVA ${ }^{1}$
}

\begin{abstract}
RESUMO: Este estudo de natureza teórica teve por objetivo realizar aproximaçóes entre os pensamentos filosóficos de Walter Benjamin e as reflexóes sociológicas de Manuel Jacinto Sarmento sobre infância, temporalidade recursiva, experiência(s) e cultura(s) infantil(is). Para tanto, dividimos nossa exposição em quatro seções que visam: evidenciar a infância como categoria histórica na modernidade; apresentar o olhar benjaminiano sobre a abordagem; evidenciar a perspectiva por meio da ótica de Sarmento; por fim, aproximar as concepçóes. Consideramos que a principal aproximação entre ambos é a de repensar o significado das dinâmicas sociais e as relaçóes dos atores sociais no contemporâneo, portanto, não apenas os sentidos da infância na atualidade, mas a própria condiçáo humana no tempo presente.
\end{abstract}

Palavras-chave: Infância. Temporalidade recursiva. Experiência. Cultura infantil. Sociologia da Infância.

\section{WILL BE THERE YESTERDAY, DADDY! — EXPERIENCE FOR CHILDREN AND CULTURES: REFLECTIONS ABOUT CHILDREN AND RECURSIVE TEMPORALITY}

\begin{abstract}
This theoretical study aims to carry out similarities between the philosophical thoughts of Walter Benjamin and sociological reflections of Manuel Jacinto Sarmento about childhood, recursive temporality, childish experiences and cultures. For this, we divided our exposition into four sessions that aim: to highlight the childhood as historical category in the modernity; to present Benjamin's look at the approach; to highlight the prospect through the Sarmento's optical; Finally, to approximate the concepts. We consider that the main approximation between from both is to rethink the meaning of social dynamics and the relations of social actors in the contemporary time, so not only the meanings of childhood today, but the own human condition at the present time.
\end{abstract}

Keywords: Childhood. Recursive temporality. Experience. Children's culture. Sociology of Childhood.

\footnotetext{
${ }^{1}$ Universidade Estadual Paulista “Júlio de Mesquita Filho" - Presidente Prudente (SP), Brasil. E-mails: eduardo.uem@hotmail.com; divino.js21@uol.com.br Fonte de financiamento: FAPESP Processo: 2013/21152-3/CAPES Processo: BEX 7915/14-4. DOI: 10.1590/ES0101-73302016138082
} 


\title{
JE VAIS LA BAS HIER, MON PÈRE! - DE L'EXPERIENCE ET DE LA CULTURE DE L'ENFANCE: DES RÉFLEXIONS SUR L'ENFANCE ET LA TEMPORALITÉ RECURSIVE
}

\begin{abstract}
RESSUME: Cette étude de nature théorique a comme objectif réalizer des approchement entre les pensances philosophiques de Walter Benjamin et les réflexions sociologiques de Manuel Jacinto Sarmento sur l'enfance, temporalité recursive, des esxpeciances et des cultures infantiles. Pour faire ceci nous avons divisé notre exposition en quatre sessions en visant: evidencier l'enfance comme catégorie historique dans na modernité; présenter le regarde benjaminian sur l'approche; mettre en evidence la perspective au moin de l'optique de Sarmento; et finalment, approcher les conceptions. En considerant que le principal approchement entre tous les deux c'est de repenser la significacion de las dinamiques sociaux et les relations des auteurs sociaux dans la comtemporanité, donc, pas seulement les sens de l'enfance dans la actualité, mais la propre condition humaine dans le temps présent.
\end{abstract}

Mots-clés: la petite enfance. La temporalité récursive. L'éxpérience. La culture des enfants. Sociologie de l'enfance.

\section{Introdução}

A

infância, tal qual a conhecemos atualmente, é fruto de uma experiência histórica a partir da Modernidade. As transformaçóes sociais produzidas pelas contradiçóes internas ao modelo feudal, que contribuíram para o surgimento do capital, impulsionaram também a humanidade a questionar as suas relaçóes. Nesse contexto, o olhar sobre a criança foi sendo modificado, estabelecendo-se uma série de novos sentimentos e concepçóes sobre a natureza da infância.

O historiador francês Philippe Ariès, na obra intitulada $A$ história social da criança e da família, publicada em 1960, evidencia que a partir do fim da Idade Média dois aspectos, ainda não experimentados sobre a infância, passaram a inseri-la na modernidade: os sentimentos de "paparicação" e de exasperação. Essas duas características contribuíram para delimitar o que é ser criança a partir de então. Se a paparicação, sentimento alimentado pela família, ajudou a formar um olhar de gentileza diante das necessidades da infância, a exasperação foi um sentimento que partiu da concepção eclesiástica de que a criança é um ser imperfeito e incompleto e que, portanto, necessita ser educado (ARIÈS, 1981). Esses aspectos analisados pelo autor mostram, na concepção dele, como a infância começa a ser valorada como categoria social, com especificidades tanto na vida pública como na vida privada e, não obstante, objeto de cuidado e de intervenção dos adultos, a partir do fim da Idade Média. 
No entanto, essa visão bastante difundida desde a publicação da obra de Philippe Ariès passou por críticas e revisitaçóes que possibilitaram expandir a compreensão da construçáo moderno-contemporânea da ideia de infância. Sobre esse aspecto, Heywood (2004) chama a atenção para os estudos posteriores que consideram fontes históricas e métodos diferenciados dos de Ariès. $\mathrm{O}$ autor se contrapóe à imagem de uma não existência da infância antes da Modernidade e afirma "a infância (assim como a adolescência) durante a Idade Média não passou tão ignorada, mas foi antes definida de forma imprecisa" (HEYWOOD, 2004, p. 29). Embora não possamos declarar a ausência de uma infância em tempos anteriores à Modernidade, é possível afirmar que foi nela que a infância ganhou destaque como objeto/projeto de reflexão filosófica, científica, educacional e política, alavancado por um (in)tenso debate sobre temas afetos ao liberalismo. Nesse sentido, não foi por coincidência que a questão apareceu de modo recorrente nos escritos e nas reflexóes de pensadores tais como Comenius, Locke, Comte, Rousseau, Kant, Condorcet, Herbart e depois deles com Freud, Piaget, Vigotski, Dewey, Montessori, Adorno, Benjamin, entre tantos outros. O fato é que em cada um a infância aparece, tímida ou explicitamente, ora como objeto de reflexão com possibilidade de intervenção, ora com a preocupação em se mapear e interpretar suas singularidades.

Entre tantas conexóes possíveis sobre a temática, gostaríamos de aproximar no que é admissível duas correntes de pensamento que são relativamente frequentes, atualmente, no contexto das reflexões sobre a infância: a Sociologia da Infância, centrando nossos esforços nos escritos do sociólogo Manuel Jacinto Sarmento, e a Filosofia, cujo foco será investido nos escritos de Walter Benjamin sobre a infância.

Sarmento (2013), em um trabalho recentemente publicado no Brasil, nos provoca sobre essa questão, ao analisar a necessidade de uma reflexão sobre a infância contemporânea que seja colaborativa, entre áreas do conhecimento.

Nesse sentido, a Sociologia da Infância não apenas está aberta
a diferentes teorias e abordagem, no seu interior - conforme
veremos - como está consciente de que não conseguirá cum-
prir seu programa teórico se não se abrir determinantemente
a um trabalho teórico interdisciplinar que contribua para im-
pedir uma visão fragmentária de criança e que seja sustentado
numa superação de dicotomias tradicionais, profundamente
redutoras da compreensáo da infância. (SARMENTO, 2013,
p. 20-21)

O sociólogo evidencia possibilidades e necessidades de abordagens que relacionem a Sociologia da Infância a outras áreas de conhecimentos, tais como a história da infância, a antropologia, a psicologia, a neurociência e a filosofia; sobre esta última é dito o que segue: 
A filosofia, e os contributos decisivos de W. Benjamin (1992) para análise da temporalidade recursiva da infância, prolongada na reflexão de Agamben (2005) sobre a criança do tempo e o contínuo processo de ampliação do mundo e das significaçôes pela redescoberta da linguagem. (SARMENTO, 2013, p. 21-22)

Para Sarmento (2003), a temporalidade recursiva é uma espécie de mecanismo que a criança utiliza para efeito de transformar, criar e recriar aspectos da realidade, "desse modo, ela incorpora no tempo presente, o tempo passado e o tempo futuro, numa sincronização de diacronias que altera a linearidade temporal, possibilita a recursividade e garante a simultaneidade de factos cronologicamente distintos" (p. 10). Esse princípio de transpor o real para o campo imaginário permite à criança interpretar os acontecimentos e as situaçóes. Nesse sentido, a noção de tempo da criança desloca-se da concepção moderna, ditada por instrumentos de precisão, como relógios e cronômetros, para uma temporalidade imaginária na qual se aproxima mais do universo onírico ou surreal. Assim, no contexto dessa percepçáo do tempo o dia tem tantas horas quanto forem interessantes para interromper o progresso objetivo dos afazeres e recomeçar tudo novamente, jogar de novo, cantar mais uma vez, brincar mais um pouco, como no mundo de Alice no País das Maravilhas.

Para aprofundar e tencionar essa perspectiva, Sarmento propóe a interdisciplinaridade como proposta de um projeto teórico de estudos da criança. Acreditamos que essa perspectiva de fato contribua para compreender náo somente o universo infantil, como também a organização do mundo contemporâneo, pois, como construção social, a infância condensa em si pistas importantes sobre o tempo presente; nesse caso, um olhar multidisciplinar e interdisciplinar pode ajudar a enxergarmos aspectos ainda não vislumbrados sobre nossa condição humana. Nesse sentido, buscamos dialogar com Benjamin para pensar a infância no contexto do projeto social burguês e os desdobramentos do moderno na vida infantil contemporânea.

\section{Infância e Modernidade}

A Modernidade é marcada por mudanças radicais no modelo produtivo e no modo de se pensar o ser e a existência do ser em tal conjuntura. Assim, a ciência, o pensamento liberal, a massificação dos processos de socialização, a segmentação do trabalho, a crescente categorização e conceituação da vida na forma de universais, as mudanças na estrutura familiar, entre outros, foram fatores que contribuíram para a emergência da infância que conhecemos na atualidade. Nesse contexto, Heywood (2004) propóe a tese de que três marcas ou passagens históricas são centrais para responder à pergunta: "qual o lugar da infância na emergência da modernidade?”. Ele se alicerça em Locke, Rousseau e no Movimento Romântico do fim do século XVIII e início do século XIX. 
O autor propóe que Locke, ao publicar a obra Algumas reflexôes sobre a educação, em 1693, funda uma concepção neutra de criança ao considerá-la uma tábula rasa. Diferente de atribuir juízo de valor positivo ou negativo sobre a criança na relação com o mundo, não a considerar nem boa nem má e, portanto, sem marcas de aculturaçáo, como um papel em branco com possibilidades infinitas de inscriçôes sociais. Tal vertente possibilita a discussão de uma educação moderna para a criança. Rousseau contribuiu para evidenciar uma oposição intensa "à tradição cristã do pecado original, com o culto da inocência original da criança" (HEYWOOD, 2004, p. 38). Essa característica de "inocência" (p. 39-41) se torna uma virtude nos escritos dos românticos do fim do século XVIII e início do século XIX, produzindo uma visão que enalteceu a imagem da infância. Esses elementos de valorizaçáo da criança na figura da infância, aos poucos, ajudaram a prolongar o tempo de "ser criança", ao passo que viabilizaram a identidade de uma infância, entendida no contexto dos românticos, "como antídoto poderoso contra as agruras e o estresse das revoluçóes Francesa e Industrial (...), na era das máquinas, a criança poderia prontamente simbolizar imaginação e sensibilidade" (p. 42).

Nessa concepção, a criança parece ter encontrado na infância uma espécie de fortaleza. Entretanto, esse "local seguro", derivado da experiência histórica da Modernidade, também é cúmplice e testemunha da racionalidade repleta de contradições que a produziu, entre elas a dupla demanda, da dimensão compulsória da condiçấo de estudante e da centralidade do cuidado no contexto da família. Inaugura-se, a partir desse movimento, segundo Sarmento (2004), a ideia da necessidade da liberação da mão de obra de trabalho infantil; a institucionalização da infância que deve ser ensinada pela escola; confia-se à família "o núcleo de convergência das relaçôes afetivas", ao mesmo tempo em que é produzido um conjunto prescritivo de saberes sobre a criança, "configuradores da administração simbólica da infância” (p. 3-5, grifo do autor).

Esses fatores - a criação da escola, o recentramento do núcleo familiar no cuidado dos filhos, a produção de disciplinas e saberes periciais, a produção da administração simbólica da infância — radicalizaram-se no final do século XX, a ponto de pontenciarem criticamente todos os seus efeitos. Assim, a escola expandiu-se e universalizou-se, as famílias reordenaram seus dispositivos de apoio e controlo infantil, os saberes disciplinares sobre a criança adquiriram autonomia e desenvolvem-se exponencialmente, e a administração simbólica adquiriu novos instrumentos reguladores. (SARMENTO, 2004, p. 5)

A imagem dessa infância se popularizou, principalmente entre a classe média, deixando à margem uma grande parcela da população infantil proveniente das camadas mais pobres, excluídas dessa espécie de seguridade social. É preciso considerar que as características que são normalmente atribuídas à infância mo- 
derna "são originalmente uma ideia de classe que, depois de um longo período de tentativa de universalização, começa a dar sinais de fracasso ou esgotamento" (SARMENTO; MARCHI, 2008, p. 107).

Essa impossibilidade de efetivação de uma infância universal, promessa moderna em torno da qual foi construído todo um ideário sobre o universo infantil, indica a necessidade de refletir sobre as reconfigurações da infância no tempo presente, pois o modo como a(s) cultura(s) infantil(is) é(são) constituída(s) sofre(m) pressão do ambiente histórico e social em que a criança se insere.

\section{Walter Benjamin e a Modernidade}

O tema cultura da criança ou cultura infantil é pouco explorado no contexto da obra de Walter Benjamin (BOLLE, 2013); no entanto, é um conceito que se pode afirmar central para a Sociologia da Infância, como veremos mais adiante neste texto. É na conjuntura de uma concepção de criança sujeito capaz de interpretar e reinterpretar o mundo e, assim, produzir conhecimentos novos sobre o mundo que se constitui a noção de temporalidade recursiva da criança, ou seja, no cerne do que se considera cultura(s) infantil(is) ou cultura da criança (BOLLE, 1984; BENJAMIN, 2013, 2002, 1987; SARMENTO, 2003, 2004, 2005a, 2005b, 2013). A transgressão do tempo socialmente demarcado, nesse contexto, se constitui como um importante recurso que expressa a capacidade de autonomia de ação e de reflexão crítica da criança sobre o mundo, segundo a condição singular infantil. Nesse sentido, nosso propósito, nesta seção, é o de pensar a noção de temporalidade recursiva da infância a partir da Filosofia de Benjamin. Apesar de serem escassos os estudos sobre a cultura da criança em Benjamin (BOLLE, 2013), temos um importante e sucinto artigo, texto de 1984 escrito por Wille Bolle, intitulado "Walter Benjamin e a cultura da infância" que inaugura o tema e nos fornece pistas para uma noção do "conceito" na obra benjaminiana.

\section{Experiência e temporalidade recursiva da criança}

A infância construída na Modernidade foi balizada por uma concepção também moderna de formação (Bildung). O homem deste tempo nasceu com a premissa e o dever de buscar em seu próprio momento histórico o novo sentido para o termo anthropos, pois "o que está em jogo aqui é a transformação do próprio conceito de sujeito" (MITROVITCH, 2011, p. 35). Ainda envolvido pela euforia da revolução burguesa, o homem moderno tem a crença na razão como canal por meio do qual seria viabilizada a sua emancipação ao ser inserido na Era das Luzes. "Esse movimento expressa a característica essencial do conceito de formação moderno: o cultivo de si; tal princípio relaciona-se com a elevação da interioridade do sujeito em direção a sua autonomia" (MITROVITCH, 2011, p. 30). 
Em tal contexto se estabelece algo que se convencionou a chamar crise da razão ou crise da modernidade. O esclarecimento (Aufklärung), como promessa de desmistificaçáo da vida e emancipaçáo humana, passou a ser direcionado para uma perspectiva de manutenção do modelo de civilidade estabelecido no século XVIII. Nesse sentido, a razão, como Aufklärung, foi convertida em sua contramão, em instrumento de (re)produção do capital (HORKHEIMER; ADORNO, 1985).

Do conjunto destas transformações — da consolidação do pensamento liberal e do capitalismo como modelo produtivo - emerge um novo perfil de formação cultural, tema que se faz central nos escritos e nas reflexôes benjaminianos sobre a experiência moderna da Bildung. Nessa vertente, indaga o autor: "pois qual o valor de todo o nosso patrimônio cultural, se a experiência não mais o vincula a nós?” (BENJAMIN, 1994, p. 115). A imagem da Bildung como formação cultural vinculada à tradição é enfraquecida pela ênfase dada ao "novo" no contexto de uma cultura de massas em plena estruturação e difusão. Os sintomas da modernidade observados e analisados pelo filósofo levam-no a considerar as tensóes fruto da transição do mundo artesanal para o urbano — da tradição, do trabalho artesanal e do tempo estendido do campo para o ambiente da exigência do novo, do trabalho alienado e do tempo espremido da cidade (MOMM, 2011) - como decisivas para a constituição humana marcada por tal mudança na configuração da Bildung.

Refletindo sobre a própria trajetória de vida, Benjamin se dá conta do peso da tradicional formação burguesa. Diferentemente de muitos outros, que caminharam no ritmo dos novos tempos, ele percebeu, além das mudanças evidentes da superfície, a continuidade do projeto histórico de uma classe. Vista assim, não só é burguesa a formação tradicional, como também a cultura de massas que a substitui; em suma: o processo de modernização como um todo. (BOLLE, 2000, p. 149)

No curso do diagnóstico sobre a Modernidade estabelecido pelo autor - na abordagem de temas como o processo de urbanização e reificação da vida; a mudança na temporalidade; a difusão da técnica na relação com a (re)produção da estética; a industrialização dos objetos da cultura da criança, entre outros - ele conclui que "está claro que as ações da experiência estão em baixa" (BENJAMIN, 1994, p. 114). Concomitante ao avanço das características da sociedade moderna ocorreu uma diminuição na capacidade humana de formar experiência, pois foi transformada a "própria estrutura dessa experiência" (BENJAMIN, 1989, p. 104). Essa perspectiva é anunciada pelo autor ao examinar o processo moderno que diluiu o sentido coletivo do tempo da experiência (Erfahrung), ao transformá-la em vivência (Erlebnis), em algo intimista, restrito ao âmbito da propriedade privada, da vida focalizada no indivíduo, tal qual a cumplicidade entre pele e veludo 
(GAGNEBIN, 1994; MITROVITCH, 2011). Nessa vertente, a Erlebnis marca o surgimento de uma nova consciência temporal oriunda da cisão entre história individual e história coletiva. O declínio da experiência (Erfahrung), portanto, aflora dessa cisão na Modernidade, como demonstra Benjamin (1994) nos ensaios O narrador, Experiência e Pobreza e Alguns temas sobre Baudelaire.

A temporalidade é algo que ele evidencia como importante para se compreender o moderno. Pragmático, o tempo desse contexto é regido pela maquinaria e materializado na forma de cronômetros e relógios. Essa objetivação da temporalidade contribuiu para romper com os laços afetivos que vinculavam, na tradição, a formação cultural (Bildung) à experiência (Erfahrung) (BENJAMIN, 1987, 1994, 2002). A partir dessa concepção de tempo que rompe com a força humanizadora e revolucionária da Bildung, Benjamin propóe outra temporalidade. Uma que permita "começar de novo, a contentar-se com pouco, a construir com pouco", pois uma saída possível é um estar aberto a operar novamente "a partir de uma tábula rasa” (BENJAMIN, 1994, p. 116).

No sentido de realizar essa proposta, Benjamin vai fundo ao encontro de suas lembranças do tempo de infância. Transforma as memórias e as lacunas a ela correspondentes em objeto de reflexão, em uma forma de reencontro com o passado para apropriar-se dele de outro modo, em um jogo que possibilite tensionar o tempo presente. Essa forma de inflexão ao tempo de infância concorre para estabelecer "uma relação profundamente ambígua, em que se misturam a todo o momento a memória afetiva e a crítica" (BOLLE, 2000, p. 345). No contexto do enfraquecimento dos laços coletivos que estruturam Bildung e Erfahrung e que, de certo modo, os unem, Benjamin busca na figura da criança a imagem de um ser aberto ao mundo e que tenta resistir à "máscara do adulto" (BENJAMIN, 2002, p. 21), por meio de "recursos lúdicos" (BOLLE, 2000, p. 147). Em "O jogo das letras", reflexão que compóe a obra Infância Berlinense por volta de 1990, o pensador afirma: "o que busco nela na verdade, é ela mesma: a infância por inteiro. (...) Assim, posso sonhar como no passado aprendi a andar" (BENJAMIN, 1987, p. 105). Afirma ainda em "Canteiro de Obras" de "Rua de mão única”:

As crianças são inclinadas de modo especial a buscarem todo e qualquer local de trabalho onde visualmente transcorre a atividade sobre as coisas. Sentem-se irresistivelmente atraídas pelos resíduos de construçóes, no trabalho de jardinagem, ou doméstico, na costura ou na marcenaria. Em produtos residuais reconhecem o rosto que o mundo das coisas exatamente para elas, e para elas unicamente. Neles, elas menos imitam as obras dos adultos do que póem materiais de espécie muito diferentes, através daquilo que com elas aprontam no brinquedo, em uma nova, brusca relaçáo entre si. Com isso as crianças formam para si seu mundo de coisas, um pequeno no grande, elas mesmas. (BENJAMIN, 1987, p. 18-19) 
Ao apresentar a tradução brasileira de 1984 da obra Reflexóes sobre a criança, o brinquedo e a educaçâo, Bolle apresenta argumentos que contribuem para ajudar a matizar o tema "cultura da criança" em Benjamin. Nesse sentido,

$\mathrm{Na}$ medida em que o autor, naquela altura com 40 anos, mergulha na memória de sua infância, ele recupera o mundo da cultura de seus pais; mas, concomitantemente, nessa volta ao tempo, recupera em certo sentido a maneira de ver da criança, a sensibilidade e os valores dela, e, sob esse ângulo, o livro se lê como se fosse um relato de criança para criança, à margem da cultura adulta (...) os escritos de Benjamin sobre cultura da criança não a considera um lugar idílico ou sentimental à parte, para onde se refugia o pessimismo da história, mas um lugar envolvido pela grande luta político-ideológica dos escritores alemães da época (...) De uma maneira geral, os brinquedos documentam como o adulto se coloca com relação ao mundo da criança. Há brinquedos muito antigos, como bola, roda, roda de penas, papagaio, que provavelmente derivam de objetos de culto e que dessacralizados, dáo margem para a criança desenvolver a sua fantasia. E há outros brinquedos, simplesmente impostos pelos adultos enquanto expressão de uma nostalgia sentimental e de falta de diálogo. Em ambos os casos, a resposta da criança se dá através do brincar, através do uso do brinquedo, que pode enveredar para uma correçâo ou mudança de função. E a criança também escolhe os seus brinquedos por conta própria, não raramente entre os objetos que os adultos jogam fora. As crianças "fazem a história a partir do lixo da história". É o que as aproxima dos "inúteis", dos "inadaptados" e dos marginalizados. (BOLLE, 1984, p. 13-14)

É a partir da noção de memória que se articula temporalidade recursiva, cultura da criança e experiência para o pensador. Assim, ao apoderar-se das memórias de infância, Benjamin, de certo modo, resgata o olhar desviante e incansável em um repertório de "imagens nas quais se evidencia a experiência da grande cidade por uma criança da classe burguesa” (BENJAMIN, 2013, p. 70). São evidentes as demissóes político-ideológicas de suas ponderaçóes, e se manifestam a partir das figuras que insurgem das reminiscências dele, linhas de uma cultura da criança e um forte significado ético e estético presente nelas. De tal modo, preocupa a Benjamin elaborar dada experiência com a infância por ele vivida em Berlim.

Essa experiência é dupla: primeiro, ela remete sempre à reflexáo do adulto que, ao lembrar o passado, não o lembra tal como realmente foi, mas, sim, somente através do prisma do presente projetado sobre ele. Essa reflexão sobre o passado visto através do presente descobre na infância perdida signos, sinais que o presente deve decifrar, caminhos e sendas que ele pode retomar, apelos aos quais deve responder pois, justamente, não se realizaram, fo- 
ram pistas abandonadas, trilhas não percorridas. Nesse sentido, a lembrança da infância não é idealização, mas, sim, realização do possível esquecido ou recalcado. A experiência da infância é a experiência daquilo que poderia ter sido diferente, isto é, releitura crítica do presente da vida adulta. (GAGNEBIN, 1997, p. 181)

Portanto, é no sentido atribuído pelo autor ao conceito de experiência que se mescla a ideia de temporalidade recursiva como ampliação das experiências sobre mundo por meio da cultura da criança.

A idéia de uma infância como uma "substância psíquica" présubjetiva revela-se entáo um mito, como aquela de um sujeito pré-linguístico, e infância e linguagem parecem assim remeter uma à outra em um círculo no qual a infância é a origem da linguagem e a linguagem a origem da infância. Mas talvez seja justamente neste círculo que devemos procurar o lugar da experiência enquanto infância do homem. Pois a experiência, a infância que aqui está em questão, não pode ser simplesmente algo que precede cronologicamente a linguagem e que, a uma certa altura, cessa de existir para versar-se na palavra, não é um paraíso que, em um determinado momento, abandonamos para sempre a fim de falar, mas coexiste originalmente com a linguagem, constitui-se aliás ela mesma na expropriação que a linguagem dela efetua. (AGAMBEN, 2008, p. 59)

$\mathrm{O}$ autor compreende que a condição de não falante do indivíduo ao nascer se traduz como figura alegórica de uma in-fância do homem assinalada por uma ausência e, portanto, também por uma busca, a da linguagem (SANCHES, 2016). Condição essa que indica uma abertura que conduz o ser humano da qualidade de não falante para a de ser falante (SANCHES, 2016); não como um dado marcado por uma fase da vida e, portanto, por um elemento cronológico, mas com uma instância que produza "cada vez mais o homem como sujeito" (AGAMBEN, 2008, p. 59).

Em Benjamin, notamos uma infância com possibilidades de a criança inverter o mundo consagrado pelo olhar do adulto, modificá-lo, profaná-lo. Tal conjuntura admite uma experiência com os acontecimentos, com a cidade, com os objetos, em outra vertente, se comparada àquela caracterizada pelas demandas do mercado de trabalho, pela "máscara do adulto", para empregarmos uma nomenclatura benjaminiana (SANCHES, 2016). Tal atributo não é algo como uma habilidade adquirida, e sim como um modo de ser no mundo entendido como "uma construção cujo lugar não é o tempo homogêneo e vazio, mas um tempo saturado de 'agoras"' (BENJAMIN, 1994, p. 229).

A noção de uma infância do homem indica a perspectiva da sensibilidade do olhar da criança, os "agoras", no sujeito adulto. Tal modo de perceber a 
condição humana como figura de uma infância do homem suporta a concepção de "fazer experiência do ser falante" (AGAMBEN, 2008, p. 17). Assim como a criança que se projeta e ousa em seus primeiros passos no início da vida, a noção de infância do homem pode ser considerada enquanto lugar de possibilidades em um ambiente social reificado e, nessa vertente, contínuo processo de ampliação do mundo e de suas possibilidades de significaçôes (SANCHES, 2016).

\section{Um atalho por Bom Retido ${ }^{1}$}

O intuito deste pequeno desvio é apenas para reverenciar e referenciar Florestan Fernandes, pesador brasileiro que inaugura de modo singular as primeiras reflexôes brasileiras sobre a noção de cultura infantil. Nosso intuito não é o de explorar esse autor em profundidade, e sim tomar o conceito estabelecido pelo pensador e alguns dos problemas por ele evidenciados como expressão de um marco inicial para as reflexôes sobre as questôes da cultura da infância dentro da Sociologia. Assim, como quem toma um pequeno atalho em uma longa jornada, passaremos de modo pontual, sucinto e bastante objetivo pelo conceito estabelecido pelo autor, a fim de na continuidade de nosso ensaio explorar os ecos dessas reflexóes, se assim podemos chamar, em alguns escritos do sociólogo português Sarmento.

Ainda em suas pesquisas de juventude, Fernandes (2004) busca realizar um estudo sobre o folclore no Estado de São Paulo nos anos 1940. Do contexto desse estudo emergem as ponderaçóes contidas no ensaio As "Trocinha" do Bom Retiro, que compóe a obra Folclore e Mudança Social na cidade de São Paulo. Nele estão os apontamentos que nos interessam, estabelecidos pelo pensador sobre a ideia de cultura infantil, conceito debatido por vários autores após Fernandes e que atualmente se constitui como um dos eixos de compreensão da Sociologia da Infância para os estudos sobre a criança no contexto mundial. Esse ensaio se trata de um registro etnográfico realizado por Florestan Fernandes e aborda a dinâmica de grupos de crianças de bairros operários na cidade de São Paulo que se reuniam após o período de aulas para brincar e que tem em Bom Retiro o local onde na ocasiáo do levantamento forneceu os subsídios para as análises do sociólogo brasileiro.

Os elementos observados nesses grupos abasteceram os argumentos para a formulação da ideia de cultura infantil. Em tais argumentos Fernandes (2004) afirma que o suporte da cultura infantil é "a sua base social" (p. 245), e que ela é "constituída de elementos culturais quase exclusivos dos imaturos e caracterizada por sua natureza lúdica” (p. 246). Ele ainda evidencia que é no cerne dos grupos infantis ou nas trocinhas, como ele prefere se referir, que se sustenta essa forma de construçáo cultural, pois, além do local de gênese, os grupos de crianças se constituem também como suporte social de socialização no qual "as crianças adquirem, em interação, os diversos elementos do folclore infantil” (p. 246). Fernandes (2004) demonstra ainda que a cultura infantil se 
constitui, em sua maior parte, de elementos oriundos da cultura adulta, mas que encontrou evidências que corroboram a hipótese de criaçáo cultural por parte das crianças nas relaçôes entre pares por meio do brincar, seja na representação de papéis como "papai e mamãe" (p. 247) ou por meio do uso de utensílios ao brincar de "casinha" (p. 248). Ao brincar, "a única coisa importante, para a criança, consiste na função social" (p. 247) daquilo que simboliza o que ela representa na brincadeira ou com o que ela brinca.

Baseado nessas observaçóes, Fernandes (2004) indica a necessidade de aprofundar os estudos sobre a socialização infantil no âmbito da relação de pares e afirma que tais evidências por ele encontradas

[colocam] os grupos infantis em equivalência com os grupos paroquiais, escolares, familiares, etc., quanto a socializaçấo da criança, agindo no mesmo sentido que estes na formaçáo do "ser social" e no desenvolvimento da personalidade dos imaturos. (p. 249)

Como veremos a seguir, apesar de não termos encontrado em Sarmento citaçôes ou a menção de Florestan Fernandes no que diz respeito aos estudos sobre a infância - o que não quer dizer que elas não aparecem em textos ou estudos aos quais não tivemos acesso - parte significativa das inquietaçóes sobre essa problemática radicada no ceio do debate da Sociologia da Infância após os anos 1990 já está contida nesse estudo que data dos anos 1940 realizado por Fernandes.

\section{Manuel Jacinto Sarmento e a Sociologia da Infância}

Manuel Jacinto Sarmento é Professor da Universidade do Minho e tem sido considerado uma referência importante no que diz respeito à Sociologia da Infância. Criou e dirigiu o Programa de Doutorado em Estudos da Criança e o Mestrado em Sociologia da Infância, além de ser membro da direção da Associação Internacional de Sociólogos de Língua Francesa (AISLF), da Associação Internacional de Sociologia (AIS), do Comitê de Pesquisa em Sociologia da Infância da AIS e da Associação Portuguesa de Sociólogos (APS).

Já a Sociologia da Infância é relativamente recente. Constitui-se enquanto campo teórico na década de 1990, no Congresso Mundial de Sociologia, em que se discute pela primeira vez sobre os processos de socialização da criança na sociedade contemporânea. Depois desse encontro, houve um crescimento exponencial na internacionalização das pesquisas sobre a infância, em que um olhar multidisciplinar e interdisciplinar foi fundamental para definir a Sociologia da Infância como um campo de pesquisas (QUINTEIRO, 2002; SARMENTO, 2005b). Daí em diante, as pesquisas passaram a contribuir para definir correntes 
de pensamento e propostas de abordagens metodológicas e a delimitar conceitos que consolidaram a Sociologia da Infância enquanto área do conhecimento.

O que buscamos nesta parte de nosso artigo é apresentar essa área do conhecimento por meio do olhar do Professor Sarmento e delimitar a temporalidade infantil, nos argumentos dele, de modo que permita aproximaçóes e distanciamentos das "infâncias de Benjamin" (SANCHES, 2016).

\section{Cultura(s) infantil(is), temporalidade recursiva da criança}

A Sociologia da Infância pode ser dividida em dois grupos que se desdobram em vertentes que têm divergências e aproximaçôes entre si. A área de Sociologia Aplicada (as perspectivas estruturais, críticas e interpretativas), a qual entende a infância como categoria social do tipo geracional e as crianças como atores sociais. O segundo segmento é a área de Estudos da Infância, que estabelece relações de cunho interdisciplinar nas pesquisas (relação interdisciplinar com a Antropologia, a Psicologia, as Ciências da Educação, a Economia, a Política Social para a Infância, entre outros), ambas estudam a infância a partir de si própria, e não do ponto de vista adultocêntrico (SARMENTO; MARCHI, 2008; SARMENTO, 2006, 2013). Nesse sentido, há um conjunto de argumentos que delimitam a área e que se constituem como convergência teórica para a Sociologia da Infância, os quais compóem a temática da citação a seguir:

Os indicadores da constituição do campo estáo todos basicamente estabelecidos: i) a delimitação conceptual da infância como categoria social e as crianças como actores sociais concretos; ii) a produção de teorias, quadros conceptuais e frames interpretativos distintos - e.g., a renovação do conceito clássico de geraçáo (Qvortrup, 2000; Alanen, 2001; Mayall, 2002; Sarmento, 2005) - a tese da "reproduçấo interpretativa" (Corsaro, 1997), os conceitos de "ofício de aluno" e de "ofício de criança” na SI francófona (Chamboredon e Prevot, 1982; Sirota, 1993) e o "construtivismo social" da infância (James, Jenks, Prout, 1998); iii) a definiçẫo de procedimentos analíticos e de metodologias investigativas privilegiadas e, se não específicas, ao menos tematicamente reorientadas pela natureza do objecto-sujeito de conhecimento: as crianças e a infância (Cristhensen e James, 2005); iv) a constituição de dispositivos de encontro e intercâmbio entre pesquisadores (especialmente os Comités de Pesquisa no interior das organizaçôes Sociológicas acima referenciadas); v) a realização de múltiplas reuniôes científicas de divulgação do conhecimento produzido e a publicaçáo de revistas e colecçôes temáticas de livros especializados; vi) a criação de programas de estudos, sobretudo de estudos avançados ao nível da pós-graduação, reportados expressamente à disciplina sic. (SARMENTO; MARCHI, 2008, p. 91-92) ${ }^{2}$ 
Dessa forma, passaremos a analisar os seis pontos assinalados na citação para uma melhor apresentação do tema proposto.

Para o autor, a marca da negação foi o princípio que governou boa parte do processo histórico que consolida a construção social e simbólica da infância (SARMENTO, 2005b; PAGNI, 2006) — in-fância — aquele que não fala; $a$-luno - aquele que não tem luz; o pedagogo — aquele que conduz a criança. Assim, a criança sempre foi vista de modo incompleto e/ou incapaz e esse modo de compreender a infância se estendeu até a Modernidade, que continuou definindo-a com parâmetros parecidos, baseando-se em uma suposta incompetência infantil - essa mesma marca pode ser verificada em Fernandes (2004) quando o pensador brasileiro se refere às crianças como "os imaturos" (p. 246). Sarmento torna evidente essa dimensão valorativa das crianças na Modernidade quando menciona que é negada voz e participação para as crianças ainda hoje, pois as excluímos do momento importante da participação social — como a impossibilidade de votar; a não participação política com a expressão da opinião e a visão infantil sobre os problemas e a gestáo pública; o planejamento das cidades com os espaços adaptados para a infância.

Nesse sentido, a Sociologia da Infância se contrapóe a essa concepção de infância e parte do princípio de que toda criança é competente, se levarmos em consideração as oportunidades e experiências que ela já pode ter na vida (SARMENTO; MARCHI, 2008). Em tal contexto, a infância não é considerada, pela interpretação da Sociologia da Infância, uma idade de transição para outra fase da vida. As crianças são entendidas como capacidades e competências ao seu modo, e, portanto, são atores sociais que expressam sua autenticidade e possibilidades no que Sarmento (2005b) chama de alteridade geracional.

A infância, enquanto categoria geracional, necessita ser estudada e articulada por meio dos elementos que homogeneízam e tornam diferentes as infâncias de uma geração, dos atributos que as diferenciam das outras gerações - mais velhas ou mais novas - e das outras categorias geracionais, como adultos e idosos. Desse modo, configura-se como um conceito-chave no campo de pesquisa, pois permitiu expandir as possibilidades da pesquisa com crianças. Esse conceito contribuiu para destacar o que é particular e que torna parecidas as crianças e as infâncias entre si, bem como os elementos de sua heterogeneidade. Ou seja, abriu-se a possibilidade de compreender o universo infantil na multiplicidade sócio-histórica do tempo presente, no contexto das desigualdades econômico-sociais; em momentos históricos distintos; enfim, em condiçôes de tornar crianças e infâncias invisíveis.

Os conceitos de "ofício de aluno" e de "ofício de criança" evidenciam o modo como instituiçóes para crianças configuram e criam normas para o desempenho social das crianças. Nelas, são desenvolvidas dinâmicas de socialização que têm ponto de partida na visão adultocêntrica da infância, e, portanto, uma relação de socialização verticalizada na mediação dos parâmetros sócio-histórico-cultu- 
rais e nas prescriçóes que direcionam a vida infantil. No entanto, as instituiçóes também são tensionadas pela infância que elas tentam aprisionar, domesticar e moldar. A criança reage ao modelo de processo civilizatório que lhe é imposto, e nesse instante ela não reproduz, e sim reinterpreta a realidade desses locais, tensionando-os, sendo, assim, protagonista do próprio crescimento e da ampliação de habilidades. Essas características observadas e desenvolvidas de modo conceitual na Sociologia da Infância permitem afirmar que, em meio à multiplicidade e à diversidade das infâncias do tempo atual, as crianças são produtoras de culturas.

$\mathrm{A}(\mathrm{s})$ cultura(s) da infância(s) expressa(m) e evidencia(m) os distintos modos por meio dos quais as crianças decodificam, representam e compartilham as suas percepçóes do mundo ao entorno. Para a Sociologia da Infância, é importante a influência da interação com pares e adultos para que haja a produção de culturas infantis. Nesse caso, tais culturas não são meras reproduçôes da visão de mundo do adulto, mas sim o resultado das relaçóes estabelecidas pela criança e o modo como ela usa os recursos de simbolização, como o jogo, o brincar, a fantasia, a temporalidade recursiva, para dotar o mundo de sentido.

Assim, a(s) cultura(s) infantil(is) está(ão), portanto, relacionada(s) ao que é produzido pela criança a partir das relaçóes por ela e com ela estabelecidas. Vinculam-se aí os instrumentos do brincar (Spielzeugen) ${ }^{3}$, bem como toda forma de interação, entre ela e o ambiente, que seja fonte de significação do mundo no contexto geracional no qual ela se insere. Tal viés compreende a infância como categoria social e a criança como sujeito em transformaçáo, que necessita aprender como agir e reagir no meio social a partir da conjuntura histórico-geracional. É entendida como um ser com demandas próprias, produtora de saberes empíricos, que carece de cuidados e proteção e é centro do processo educacional (SARMENTO, 2003, 2004, 2005a, 2011, 2013).

Compreendemos que o objeto-sujeito de que trata a Sociologia da Infância e tanto ela reivindica é a infância em si mesma, no sentido de que se deve destacar o protagonismo e o olhar da infância sobre si mesma, naquilo que ela se distingue de outras gerações e em oposição ao olhar adultocêntrico, que toma a criança como a priori. Isso implicou formas de abordagens metodológicas de pesquisa que transferissem o poder de fala para a criança para que ela pudesse nomear a infância a partir de si mesma, do ponto de vista dela (SARMENTO; MARCHI, 2008). Em um estatuto social cujas profundas e aligeiras transformaçóes sociais da Modernidade trouxeram efeitos nas condiçóes de vida das crianças e no estatuto social da infância, elas também interpretaram as mudanças do mundo a sua maneira. No cenário posto, um importante papel da Sociologia da Infância é ajudar a compreender as relaçóes entre criança e sociedade e vice-versa, o que envolve, em um projeto social mais amplo, o compromisso ético de promoção dos direitos e da cidadania da infância, "isto é, a ciência que busca o conhecimento dos fatos sociais, através das e com as crianças” (SARMENTO, 2006). 


\section{Considerações finais}

Observar a infância aproximando categorias reflexivas é algo necessário tanto quanto complexo. Cada categoria parte de princípios muito particulares, próprios do eixo científico da área das Ciências Humanas de onde emerge. Acreditamos que essas sejam as dificuldades maiores em tentar realizar o exercício de pensamento que tentamos objetivar no espaço deste estudo e também nosso limite.

Assim, foi possível compreender que Benjamin parte da criança real, realizada e realizável em si mesma, a mesma analisada na Sociologia da Infância, para tornar filosófico o ser infantil como alegoria de uma experiência temporal específica, a temporalidade recursiva da criança. Se para a Sociologia da Infância a temporalidade infantil viabiliza para a criança a produção de culturas infantis, a metáfora desse tempo permite a Benjamin criticar o processo civilizatório que tornou real o pesadelo nazista. Ao refletir sobre a infância em Berlim, o filósofo tem a possibilidade de resgatar a humanidade da infância e o olhar não petrificado pela "máscara do adulto", ao passo que questiona que humanidade era aquela do tempo presente dele que aceitava tal perspectiva de ética social e bem comum. Benjamin, dessa forma, resgata, enquanto adulto, a temporalidade recursiva que ele aprendeu na infância. Fortalece, assim, a ideia da necessidade de uma infância do/no homem, não como uma experiência cronológica nem somente ligada à ideia da criança do século XX, mas como uma condição de ser e estar no mundo.

Em Sarmento podemos verificar, por meio dos pontos relacionados, que só é possível compreender a temporalidade recursiva da criança se vinculada aos conceitos de reproduçáo interpretativa, de categoria geracional e cultura(s) infantil(is). Ou seja, a experiência do tempo e com o tempo no século XVIII foi bem diferente da que é possível experienciar no século XXI. No entanto, os relatos históricos demonstram que as crianças sempre tiveram de modo mais ou menos intenso uma espécie de protagonismo de si, olhar desviante para a realidade e um modo de estar no mundo governado por recurso de percepção do tempo e das coisas que a permitem estabelecer o (re)criar, o fantasiar, o brincar, componentes imprescindíveis no contexto da(s) cultura(s) infantil(is). Vinculam-se aí os instrumentos do brincar, bem como toda forma de interação, entre ela e o ambiente, que produza significação no contexto geracional em que ela se insere.

Desse modo, o tempo da infância na Sociologia da Infância é o tempo da criança enquanto criança, que no agora produz cultura — seja ela radicada em Fernandes ou nos autores que emergem pós-1990 — , ao passo que em Benjamin é o tempo filosófico que se estrutura por uma concepção alegórica da temporalidade, portanto não linear e não cronológico, o que coincide com o modo recursivo da temporalidade infantil. Em outro sentido, não comparativo, Benjamin diz que a inclinação para com a própria infância é uma tentativa do reencontro de uma infância plena em si para reivindicar a plenitude da infância do homem. No en- 
tanto, essa dimensão alegórica remete também para a infância do tempo presente, como um desejo de que as infâncias do século XXI possam ter memórias narráveis, humanizadoras.

Reflexôes, como as desenvolvidas neste estudo, demonstram que não se trata de apenas conceituar a infância em suas potencialidades como espaço de vida importante no desenvolvimento das capacidades humanas. No contexto da sociedade de massas, pode-se notar que a temporalidade recursiva da criança adquire características que ultrapassam a condição da manipulação do tempo em si. Ela incorpora tendências em que a própria identidade infantil se dissolve e se reintegra. Assim, a criança se apodera, constrói e transforma a si mesma e o entorno dela. $\mathrm{O}$ recurso de manipulação do tempo constitui-se, portanto, parte integrante dos processos de apreensão da realidade ou como vivência criativa nas experiências de aprendizagem.

Como margem no exposto, a reorganização mercantil e pragmática que se imprimiu ao conceito de temporalidade na sociedade de consumo atual requer uma urgente reflexão. Não apenas sobre a condição da infância, mas sobre as condiçôes sociais que ainda massacram e usurpam a vida humana como forma de legitimar um modelo produtivo. Nesse caso, a Sociologia da Infância concorre para efetivar uma antiga reivindicação de Benjamin. Ora se não é esta a grande busca da Sociologia da Infância, a de valorar a infância como tal e todo o potencial da criança protagonista, que participa, cria, recria, transforma e influencia ativamente no contexto das relaçôes que ela estabelece? Essa exigência transcende um pensar exclusivo sobre a infância e visa repensar as condiçóes da própria vida em sociedade.

\section{Notas}

1. Apesar das contribuiçôes inegáveis de Florestan Fernandes para uma mudança no paradigma sobre as produções infantis e a visão do adulto sobre a condição da criança, principalmente no contexto da investigação sobre a infância, nosso intuito não é o de estabelecer um levantamento dos argumentos do pensador brasileiro sobre tal abordagem. Tampouco o de realizar um levantamento dentro das produçóes brasileiras neste momento. Nosso foco e esforço estão centrados na produção após a constituição da Sociologia da Infância datada da década de 1990 e especificamente no contexto das produçōes de Sarmento. Esse arranjo se justifica pela produção realizada pelo autor português ter nos inspirado e mostrado caminhos para uma investigaçáo cujo intuito foi o de pensar as aproximaçôes possíveis entre Walter Benjamin e a Sociologia da Infância que se derivaram a partir do marco de sua instituição como campo de estudos. Para uma busca sobre a abordagem feita por Florestan Fernandes, verificar: FERNANDES, Florestan. Folclore e mudança social na cidade de São Paulo. 3. ed. São Paulo: Martins Fontes, 2004.

2. Caso haja interesse no aprofundamento em alguns dos assuntos contidos na citaçáo, segue uma relação com as referências mencionadas no excerto: 
ALANEN, L. Explorations in Gerational Analysis, In: ALANEN, L.;MAYALL, B. (Org.). Conceptualizing Child-Adult Relations. London: Routledge, 2001. p. 11-22.

CHAMBOREDON, J.C.; PRÉVOT, J. O ofício de criança. In: GRÁCIO, S.; STOER, S. Sociologia da Educação II. Antologia - A Construção Social das Práticas Educativas. Lisboa: Livros Horizonte, 1982. p. 51-77.

CHRISTENSEN, P.; JAMES, A. (Org.). Investigação com crianças: perspectivas e práticas. Porto: Edições ESEPF, 2005.

CORSARO, W.A. The Sociology of Childhood. Thousand Oaks: Pine Forge Press, 1997.

JAMES, A.; JENKS, C.; PROUT, A. Theorizing Childhood. Cambridge: Polity Press, 1998.

MAYALL, B. Towards a Sociology for Childhood. Thinking from children's lives. Buckingham: Open University Press, 2002.

QVORTRUP, J. Generations - an important category in sociological research. In: Vários, Actas do Congresso Internacional dos Mundos Sociais e Culturais da Infância, v. 2, p. 102-113, 2002.

SARMENTO, M. J. Geraçôes e Alteridade: interrogações a partir da Sociologia da Infância. Educação e Sociedade, v. 26, n. 91, , p. 361-378, 2005.

SGRITTA, G.B. Inconsistencies: Childhood on Economic and Political Agenda. Childhood, v. 4, n. 4, p. 375-404, 1997.

3. "Quando as crianças opóem-se à visão convencional de um playground fabricado com base em especulações pedagógicas, subindo quando a norma manda descer, descendo por onde os dispositivos disciplinares mandam subir e salvando materiais ao dar destaque às embalagens, às garrafas, às tampas e pedrinhas encontradas que se transformam em instrumentos de brincar (Spielzeugen = brinquedos), estabelecem relações com materiais “inúteis", retirando da obscuridade o marginal, o periférico, os cacos (de sua história, poderíamos dizer). E, em seu trato com esses instrumentos, revelam a possibilidade do valor de uso àqueles que observam com atenção às imagens por elas fornecidas" (RICHTER; VAZ, 2005, p. 90).

\section{Referências}

AGAMBEN, G. Elogio da profanação. In: . Profanações. São Paulo: Boitempo, 2007. p. 65-79.

Infância e História: destruição da experiência e origem da história. Belo Horizonte: UFMG, 2008.

ARIÈS, P. História Social da Criança e da Família. 2. ed. Rio de Janeiro: Editora Guanabara, 1981. BENJAMIN, W. Obras escolhidas II. São Paulo: Brasiliense, 1987.

. Obras escolhidas III. São Paulo: Brasiliense, 1989.

. Obras escolhidas I. São Paulo: Brasiliense, 1994. 
Ed. 34, 2002.

Reflexôes: a criança, o brinquedo e o brincar, a educação. São Paulo: Duas Cidades;

Rua de mão única: Infância berlinense: 1900. Belo Horizonte: Autêntica Editora, 2013.

BOLLE, W. W. Benjamin e a cultura da criança. [mensagem pessoal]. Mensagem recebida por<eduardo.uem@hotmail.com> em 12 set. 2013.

Walter Benjamin e a cultura da criança. In. BENJAMIN, W. Reflexóes: a criança, o brinquedo e o brincar, a educação. São Paulo: Summus, 1984. p. 13-16.

Fisiognomia da metrópole moderna: representaçóes da história em Walter Benjamin. São Paulo: Edusp, 2000.

FERNANDES, F. As "trocinhas" do Bom Retiro. Revista Pro-Posilçóes, v. 15, n. 1 (43), p. 229-250, 2004.

GANGNEBIN, J.M. Sete Aulas Sobre, Linguagem, Memória e História. Rio de Janeiro: Mago Ed, 1997.

Préfácil - Walter Benjamin e a história aberta. In: BENJAMIN, W. Obras escolhidas I. São Paulo: Brasiliense, 1994.

HEYWOOD, C. Uma História da infância: da Idade Média à época contemporânea no ocidente. Porto Alegre: Artmed, 2004.

HORKHEIMER, M.; ADORNO, T.W. Dialética do esclarecimento: fragmentos filosóficos. Rio de Janeiro: Zahar Ed., 1985.

MITROVITCH, C. Experiência e Formação em Walter Benjamin. São Paulo: Editora Unesp, 2011.

MOMM, C.M. Sobre infância e sua educação: Walter Benjamin e Hannah Arendt. Tese (Doutorado) - Universidade Federal de Santa Catarina, Centro de Ciências da Educação, Programa de Pós-Graduação em Educação, Florianópolis, 2011.

PAGNI, P.A. Infância. In: CARVALHO, A.D. (Coord.). Dicionário de filosofia da educação. Porto: Porto Editora, 2006. p. 212-220.

QUINTEIRO, J. Sobre a emergência de uma sociologia da Infância: contribuiçôes para o debate. Perspectiva, v. 20, n. esp., p. 137-162, 2002.

RICHTER, A.C.; VAZ, A.F. Corpos, saberes e infância: um inventário para estudos sobre a Educação do corpo em ambientes Educacionais de 0 a 6 anos. Revista Brasileira de Ciências do Esporte, v. 26, n. 3, p. 79-93, 2005.

SANCHES, E.O. As infâncias de Benjamin, uma possibilidade de experiência com o moderno. In: Educação e Filosofia. Uberlândia, 2016. (no prelo).

SARMENTO, M.J. Imaginário e culturas da infância. Cadernos de Educação, v. 12, n. 21, p. 51-69, 2003.

As culturas da infância nas encruzilhadas da $2^{a}$ modernidade. In: SARMENTO, M.J.; CERISARA, A.B. (Org.). Crianças e miúdos: perspectivas sócio-pedagógicas da infância e educação. Porto: Asa, 2004. p. 9-34. 
Crianças: educação, culturas e cidadania ativa. Refletindo em torno de uma proposta de trabalho. Perspectiva, v. 23, n. 1, p. 17-40, 2005 a.

Geraçôes e Alteridade: interrogaçôes a partir da Sociologia da Infância. Educação e Sociedade, v. 26, n. 91, p. 361-378, 2005b.

. Mapa de Conceitos na área de estudos da Sociologia da Infância. Revista Eletrônica Zero-a-seis, n. 14, 2006. Disponível em <http://www.ced.ufsc.br/-zeroseis/resenha14. html>. Acesso em: 07 maio 2014.

A reinvenção do ofício de criança e de aluno. Atos de Pesquisa em Educação, v. 6, n. 3, p. 562-571, 2011.

A sociologia da infância e a sociedade contemporânea: desafios e praxeológicos. In: ENS, R.T.; GARANHANI, M.C. (Org.) A sociologia da infância e a formação de professores. Curitiba: Champagnat, 2013. p. 13-46.

.; MARCHI, R.C. Radicalização da infância na segunda modernidade: para uma Sociologia da Infância crítica. Configuraçôes, Revista do Centro de Investigação em Ciências Social da Universidade do Minho, n. 4, p. 91-113, 2008.

Recebido em 22 de julho de 2014.

Aceito em 12 de abril de 2016. 